\title{
Cardiac Wall
}

National Cancer Institute

\section{Source}

National Cancer Institute. Cardiac Wall. NCI Thesaurus. Code C139201.

All of the tissue that comprises the solid, outer structure of the heart, including the epicardium, the myocardium, and the endocardium. 